Hoyles plate should be identified. Non-toxigenic strains can produce local symptoms similar to those caused by toxigenic strains and previous immunisation does not alter the incidence of these symptoms. ${ }^{34}$ In addition to the Elek test, tests for pyrazinamidase and cystinase to screen for non-toxigenic and toxigenic species have been advised. ${ }^{5}$ In this case, the child carrying the toxigenic strain had neither symptoms nor signs of infection and the mother had suggestive signs but without positive cultures.

1 Wilson APR, Ridgway GL, Grüneberg RN, Efstratiou A, Colman G, Cookson B. Routine screening fo Corynebacterium diphtheriae. Lancet 1990;336:1199.

Masterton RG, Tettnar RE, Pile RLC, Jones J, Croft KF. Immunity to diphtheria in young British adults. $\mathcal{f}$ Infection

3 Barksdale L, Garmise L, Horibata K. Virulence, toxinogeny and lysogeny in Corynebacterium diphtheriae. Ann NY and lysogeny in Corynebact

4 Bennett JV, Brooks GF, Feldman RA. Clinical diphtheria from nontoxigenic Corynebacterium? $\mathcal{f}$ Infect Dis 1975;131:496-8.

5 Colman G, Weaver E, Efstratiou A. Screening tests for pathogenic corynebacteria. $\mathcal{F}$ Clin Pathol 1992;45:46-8.

\title{
Severe thrombocytopenia secondary to asymptomatic cytomegalovirus infection in an immunocompetent host
}

\author{
J G Wright
}

\begin{abstract}
A healthy 33 year old man presented with a short history of purpura and easy bruising. Investigations showed profound thrombocytopenia with atypical lymphocytes in the peripheral blood. Marrow appearances were consistent with platelet consumption. Biochemical hepatitis was also noted. An infection screen showed the underlying diagnosis to be cytomegalovirus (CMV) infection. He was treated successfully with oral prednisolone. This subsequently tailed off without relapse.

Careful examination of a stained blood film is needed in all cases of apparent idiopathic immune thrombocytopenic purpura.
\end{abstract}

(F Clin Pathol 1992;45:1037-1038)

The most common form of cytomegalovirus (CMV) infection in the immunocompetent is asymptomatic and usually detected retrospectively. It is a well recognised cause of a "glandular fever"-like illness characterised by myalgia, malaise, headache, fever and sore throat. ${ }^{1}$ Peripheral blood examination shows the atypical mononuclear cells present in all causes of this symptom complex-for example, Epstein Barr virus infection, toxoplasmosis, $Q$ fever. The illness is usually self limiting and serious complications (such as haemolysis, Guillain-Barré syndrome, granulomatous hepatitis, carditis, pneumonia and meningoencephalitis), though well recognised, are rare.

Although thrombocytopenia is well described in congenital CMV infection, ${ }^{2}$ there are only three recorded cases in otherwise healthy individuals. ${ }^{35}$ We report a case of a man with acquired CMV infection presenting with pur- pura and bruising in the absence of other symptoms.

\section{Case report}

A 33 year old male newsagent presented with a three day history of purpura, epistaxis, and easy bruising. He was otherwise asymptomatic and receiving no drugs. Examination showed that he was a healthy apyrexial man. There was extensive purpura over his limbs and trunk with haemorrhagic bullae in his mouth. Fundoscopy yielded normal results. There was no lymphadenopathy or hepatosplenomegaly.

Full blood count showed a platelet count of $5 \times 10 \times 9 / 1$ and a lymphocytosis $(4.8 \times 10$ $\times 9 / 1)$ with atypical mononuclear cells. The Monospot test was persistently negative. Sternal marrow appearances were consistent with thrombocytopenia due to peripheral consumption; megakaryocyte morphology was normal. Coagulation screen was normal apart from a prolonged KCCT at $47 \cdot 3$ seconds (normal range 30-41), and tests for lupus-like anticoagulant (dilute Russell viper venom time with platelet neutralisation procedure) were positive; anticardiolipin antibodies were not detectable. Liver function tests showed raised transaminases (ALT $288 \mathrm{IU} / 1$, AST $88 \mathrm{IU} / 1$, alkaline phosphatase $14 \mathrm{IU} / \mathrm{l}$, and glutamyl transferase $136 \mathrm{IU} / \mathrm{l}$ ). Hepatitis screen (including hepatitis $\mathrm{A}, \mathrm{B}$, and $\mathrm{C}$ ), autoantibodies including antinuclear antibody, rheumatoid factor, and anti-double stranded DNA were negative. CMV titres performed on the day following admission showed a titre of 320 with anti-CMV IgM detected, indicative of recent infection.

Treatment with prednisolone $80 \mathrm{mg}$ per day was started shortly after admission. The platelet count was initially slow to respond; at 
discharge on day seven the count was $32 \times 10$ $x^{9} / 1$. By day 27 the platelet count was greater than $150 \times 10 \times 9 / 1$ and it has remained above this since. The prednisolone was reduced to 40 $\mathrm{mg} /$ day on day 18 and tailed down to zero over eight weeks. Serial measurements of transaminase activities showed a progressive return to normal by week six. Repeat tests for lupus anticoagulant and anticardiolipin antibodies were performed when the patient had finished all treatment with a normal count. These were normal.

\section{Discussion}

Thrombocytopenia is frequently seen following Epstein Barr virus infection, though rarely with CMV. The self limiting biochemical hepatitis, without clinical manifestations, which prompted measurement of CMV titres is a common accompaniment to $\mathrm{CMV}$ infection occurring in over $90 \%$ of patients with CMV mononucleosis. ${ }^{6}$ High fever is the most common feature of CMV infection but was absent in this patient. The delayed rise in platelet count following the introduction of steroids could represent a spontaneous recovery rather than a prednisolone related increase. The marrow findings supported a consumptive mechanism and disseminated intravascular coagulation was not present. Platelet associated IgG was not measured; we have pre- viously noted increased concentrations in many types of liver disease, suggesting a nonspecific increase. ${ }^{7}$ However, the detection of a lupus anticoagulant supports an immune mechanism for platelet destruction as similar findings have been noted in a proportion of subjects with (auto)-immune thrombocytopenic purpura (ITP). ${ }^{8}$

CMV infection is not well recognised as a cause of severe symptomatic thrombocytopenia. This case reinforces the need for careful examination of a stained blood film in all cases of apparent "idiopathic" ITP and suggests that liver enzyme activities and CMV serology should be included in the diagnostic assessment of selected cases.

1 Klemdääriäinen L. Cytomegalovirus as a possible cause of a disease resembling infectious mononucleosis. $\mathrm{Br} \mathrm{Med} f$ 1965;2:1099-102.

2 Oski FA, Naeman IL Haematological problems in the newborn. 2nd Ed. Philadelphia: J B Lippincott, 1972.

3 Chanarin I, Walford DM. Thrombocytopenia in cytomegalovirus mononucleosis. Lancet 1973;ii:238-9.

4 Ip H, Corner BD. Thrombocytopenic purpura in cytomegalovirus mononucleosis. Lancet 1973;ii:62.

5 Fiala M, Kattlove H. Cytomegalovirus mononucleosis with severe thrombocytopenia. Ann Intern Med 1973;79:
s. severe

6 Cohen JI, Ralph Corey G. Cytomegalovirus infection in the normal host. Medicine 1985;64:100-14.

7 de Noronha R, Taylor BA, Wild G, Triger DR, Greaves $M$. Inter-relationships between platelet count, platelet IgG, immune complexes and severity of liver disease. Clin Lab Haematol 1991;13:127-35.

8 Harris EN, Gharavi AE, Hegde U, Derne G, et al. Anticardiolipin antibodies in autoimmune thrombocytopenic purpura. Br f Haematol 1985;59:231-4. 